\title{
Direitos e seguridade social em tempos neoliberais: contradições e desafios feministas
}

\author{
Laudicena Barreto ${ }^{1}$ \\ https://orcid.org/0000-0001-5131-1528 \\ ${ }^{1}$ Universidade Federal de Pernambuco, Departamento de Serviço Social, Recife, PE, Brasil
}

\section{Direitos e seguridade social em tempos neoliberais: contradições e desafios feministas}

Resumo: As políticas de ajustes neoliberais no Brasil avançam sobre a Seguridade Social porque têm um pressuposto: a exploração do tempo, dos corpos e do trabalho das mulheres das classes subalternas. Dessa compreensão, este artigo tem como objetivo refletir sobre os desafios feministas quanto à direção das lutas em torno da proteção social para as mulheres numa conjuntura em que se acirram as políticas neoliberais e o desmonte da Seguridade Social. A partir de ampla revisão bibliográfica e análise de documentos que versaram sobre as contradições em torno da conquista à aposentadoria para as donas de casa de baixa renda nos governos do PT, argumenta-se que as lutas feministas por direitos não podem prescindir de uma compreensão analítica sobre os mecanismos estruturais e conjunturais que aprisionam, discriminam, exploram e oprimem as mulheres, dentre os quais: a divisão sexual do trabalho.

Palavras-chave: Divisão sexual do trabalho. Seguridade social. Neoliberalismo. Desafios feministas.

\section{Rights and social security in neoliberal times: feminist contradictions and challenges}

Abstract: The policies of neoliberal adjustments in Brazil advance on Social Security because they have an assumption: the exploitation of time, bodies and work of women of the lower classes. From this understanding, this article aims to reflect on the feminist challenges regarding the direction of the struggles around of the Social Protection for women in a context where neoliberal policies and the dismantling of Social Security are intensifying. From the extensive literature review and analysis in doctoral documents, which dealt with the contradictions surrounding the achievement of retirement for low-income housewives in PT governments, it is argued that feminist struggles for rights cannot do without. an analytical understanding of the structural and conjunctural mechanisms that imprison, discriminate, exploit and oppress women, including: the sexual division of labor.

Keywords: Sexual division of labor. Social Security. Neoliberalism. Feminist challenges.

Recebido em 29.10.2019. Aprovado em 11.02.2020. Revisado em 02.04.2020

(C) O(s) Autor(es). 2020 Acesso Aberto Esta obra está licenciada sob os termos da Licença Creative Commons Atribuição-NãoComercial 4.0 Internacional (https://creativecommons.org/licenses/by-nc/4.0/deed.pt_BR), que permite copiar, distribuir e reproduzir em qualquer meio, bem como adaptar, transformar e criar a partir deste material, desde que para fins não comerciais e que você forneça o devido crédito aos autores e a fonte, insira um link para a Licença Creative Commons e indique se mudanças foram feitas. 


\section{Introdução}

É consenso que a era Lula foi marcada por contradições (SINGER, 2012) e uma delas está balizada na conquista das "donas de casa de baixa renda" contribuir para a Previdência Social. Conforme discutido em Barreto (2019; 2016), ao passo que o governo do PT avançava com os mecanismos de desmonte da Seguridade Social, especialmente, de mais uma contrarreforma da Previdência Social; instituía, pari passu, um novo mecanismo que possibilitaria garantir o direito à Previdência Social de segmentos historicamente invisibilizados e socialmente desprotegidos, qual seja: o denominado Sistema Especial de Inclusão Previdenciária (SEIP). (BRASHL,19881).

O SEIP foi regulamentado em 2011 por meio da Lei n. 12.470 (BRASIL, 2011) que consolidou o instituto da alíquota diferenciada de contribuição de 5\% para o e a microempreendedor/a individual - o denominado MEI - e para o segurado e segurada facultativa sem renda própria que se dedique exclusivamente ao trabalho doméstico no âmbito de sua residência e pertencente à família de baixa renda, a exemplo da "dona de casa de baixa renda".

Diferentemente do $\mathrm{MEI}^{2}$, para que a "dona de casa de baixa renda"”s possa adquirir o direito à aposentadoria $\mathrm{e}$ aos benefícios previdenciários, o Estado por meio de suas instituições estabelecem requisitos ${ }^{4}$ que parecem reforçar a reprodução dos mecanismos de discriminação, dominação e opressão às mulheres das classes subalternas, quais sejam: 1) Não possuir renda própria de nenhum tipo - incluindo aluguel, pensão alimentícia, pensão por morte, entre outros valores; 2) Não exercer atividade remunerada e dedicar-se apenas ao trabalho doméstico, na própria residência; 3) Possuir renda familiar de até dois salários mínimos - a renda do Programa Bolsa Família não entra para o cálculo; 4) Estar inscrito no Cadastro Único para Programas Sociais (CadÚnico), com situação atualizada nos últimos dois anos (BARRETO, 2019).

Nesses termos, um primeiro aspecto a se refletir diz respeito ao fato de que o direito das "donas de casa de baixa renda" de contribuir para a Previdência Social se constitui em avanço no campo das conquistas sociais; mas, ele não prescinde do pressuposto liberal que funda a condição de segurado da Previdência Social, qual seja: o caráter contributivo ${ }^{5}$.

Pelo exposto, a questão está em o Estado exigir contribuição de um segmento que supostamente deverá se dedicar exclusivamente ao trabalho doméstico e ao mesmo tempo determinar que as denominadas "donas de casa de baixa renda" não possam ter renda. Conforme os requisitos expostos acima, a única renda permitida é a do Programa Bolsa Família.

Dentre outros aspectos, os nossos estudos revelaram que a criação do Sistema Especial de Inclusão Previdenciária forjou-se e consolidou-se na dinâmica contraditória da expansão seletiva e privatista da Previdência Social ${ }^{6}$ nos governos do PT, alicerçando sob três di-

[...] a luta pelo direito humano à proteção social, em especial, à Seguridade Social, é uma luta feminista de resistência às políticas neoliberais que pode possibilitar às mulheres, em especial àquelas das classes subalternas, as condições objetivas e subjetivas para resistir à exploração, opressão e discriminação dos seus corpos. $O$ que revela que a luta feminista por direitos tem o potencial de ser uma luta anticapitalista, antipatriarcal e antirracista, portanto, revolucionária. mensões articuladas, o avesso da conquista para as "donas de casa de baixa renda", a saber: a exploração e opressão não só pelo Estado, mas pelos outros sujeitos das suas relações; a ultraprecarização do trabalho como alternativa para garantir a contribuição sistemática à Previdência Social; e, a ultravalorização do Programa Bolsa Família como sustentação das políticas de reprodução social, denotando tanto o desmonte de um sistema de proteção social universal, como ampliando os mecanismos de regressividade do direito à Seguridade Social, liberando, portanto, o Fundo Público em favor do capital financeiro (BARRETO, 2019).

Com efeito, tomando por referência o tempo mínimo de contribuição para a Previdência Social ${ }^{7}$, observamos que à medida que a "dona de casa de baixa renda" vá atingindo a idade de aposentadoria, em média, 45 anos de idade, o Estado brasileiro terá durante 15 anos, no mínimo, um quantitativo de mulheres dedicadas 
exclusivamente ao trabalho doméstico não remunerado e de cuidados. Concretamente, o que isso significa? Em linhas gerais, significa mais mulheres discriminadas, exploradas e oprimidas não só pelo Estado, mas pelos outros sujeitos das suas relações, a exemplo de seus maridos, companheiros/as, filhos, outros e outras, inclusive, que irão subsidiar a contribuição à Previdência Social (BARRETO, 2019).

Dessa perspectiva, está posto que a dinâmica da reprodução social em tempos neoliberais tem implicações e revelam sob que condições, objetivas e subjetivas, a chamada "dona de casa de baixa renda" estará garantindo a contribuição à Previdência Social, sobretudo, quando nos referimos às mulheres "chefes de família", pauperizadas e negras da periferia que historicamente se submetem aos trabalhos desprotegidos para obter renda e garantir a sua sobrevivência e de seus dependentes (BARRETO, 2019).

Pelo exposto, a regulamentação do direito à aposentadoria para as "donas de casa de baixa renda"-em contexto de crises e avanço da mundialização financeirizada do capital e do ideário neoliberal ", parece ter revelado contradições, mas, sobretudo, desafios no campo das lutas feministas ${ }^{8}$ em defesa dos direitos de Seguridade Social das mulheres, especialmente, as das classes subalternas.

Isto posto, este artigo que se constituiu a partir de ampla revisão bibliográfica e análise de documentos que visaram compreender as contradições em torno da conquista da aposentadoria para as "donas de casa de baixa renda" no contexto dos governos do PT (BARRETO, 2019), tem como objetivo refletir sobre os desafios feministas quanto a direção das lutas sociais numa conjuntura de acirramento das políticas ultraneoliberais e do neoconservadorismo no Brasil e no mundo que tem no tempo, nos corpos e no trabalho das mulheres das classes subalternas o seu alicerce (BARRETO, 2019; DUQUE-ARRAZOLA, 2004; FERREIRA, 2017).

Além desta introdução, que expõe o avesso da conquista do direito à aposentadoria para as "donas de casa de baixa renda", acrescentamos mais duas partes didaticamente articuladas. No desenvolvimento deste artigo abordamos sobre a divisão sexual do trabalho, trabalho doméstico não remunerado e seguridade social em tempos neoliberais, demonstrando que há uma sobrecarga desse trabalho para as mulheres das classes subalternas, o que exige a defesa e garantia do direito humano à proteção social materializado em políticas, bens e serviços públicos universais de reprodução social. Ao final, ancorada em estudos feministas recentes, refletimos que a luta pelo direito humano à proteção social, em especial, à Seguridade Social, é uma luta feminista de resistência às políticas neoliberais que pode possibilitar às mulheres, em especial àquelas das classes subalternas, as condições objetivas e subjetivas para resistir à exploração, opressão e discriminação dos seus corpos. O que revela que a luta feminista por direitos tem o potencial de ser uma luta anticapitalista, antipatriarcal e antirracista, portanto, revolucionária.

\section{Divisão sexual do trabalho, trabalho doméstico e seguridade social em tempos neoliberais}

A “compra de força de trabalho pelo capital é o processo mais importante em termos de valorização, já que essa mercadoria é a única que tem a capacidade de gerar um valor extra, superior ao que vale" (OSÓRIO, 2012, p. 50) e, portanto, gerar lucro e acumular cada vez mais riqueza para garantir a reprodução ampliada do capital. Contudo, a mercadoria força de trabalho precisa estar em condições de ser explorada. Encontram-se aqui, conforme destaca o estudioso, as necessidades referentes à alimentação, vestuário, habitação, educação, saúde dentre tantas outras. Nesse sentido, no âmbito da relação capital-trabalho, ou seja, na singularidade objetiva e subjetiva em que está constituída a relação entre explorador e explorado, "o trabalhador deve encontrar o conjunto de condições indispensáveis para produzir e reproduzir a sua força de trabalho, e dentro delas o salário é importante, mas não é o único elemento" (OSÓRIO, 2012, p. 51).

Lembremos que a força de trabalho é uma mercadoria especial, pois, por sua natureza humana, requer como bem destaca Ferreira (2017, p. 92) ao referenciar Marx, "um processo contínuo de manutenção e reposição da energia corporal e, ainda, de atividades relacionadas à 'modificação de sua natureza' para adequá-las às exigências das relações de produção - socialização, educação, disciplinamento, valores morais". Nesses termos, a pesquisadora feminista destaca que, "o capital utiliza-se da divisão sexual do trabalho para fins de aprofundar a exploração e ampliar a acumulação" (FERREIRA, 2017, p. 66). Para a autora, isso ocorre tanto ao explorar o trabalho das mulheres no mercado de trabalho, sob rendimentos rebaixados, como pela apropriação do trabalho doméstico realizado gratuitamente para suas famílias na esfera da reprodução social (Idem, Ibidem).

De acordo com Kergoat (2009, p. 67), a divisão sexual do trabalho é a forma de divisão do trabalho social decorrente das relações sociais de sexo. Nas palavras da autora, "esta forma é adaptada historicamente e a cada sociedade". E acrescenta, "ela tem por características a destinação prioritária dos homens à esfera produtiva e das mulheres à esfera reprodutiva e, simultaneamente, a apreensão pelos homens das funções de forte valor social agregado (políticas, religiosas, militares etc.)". 
Vale salientar, conforme afirma a pesquisadora francesa, que as formas da divisão sexual do trabalho são extremamente instáveis no tempo e no espaço, mas isso não afeta o fato de que há dois princípios organizadores, o princípio da separação e o princípio da hierarquia. Nos termos de Danièle Kergoat, "o princípio de separação (existem trabalhos de homem e trabalhos de mulheres) e o princípio de hierarquização (um trabalho de homem "vale" mais do que um trabalho de mulher)" (KERGOAT, 2009, p. 67).

Do ponto de vista histórico é a sociedade capitalista que inaugura a atual estrutura da divisão sexual do trabalho em que o trabalho produtivo não poderia ocorrer sem o trabalho doméstico vinculado às mulheres. $\mathrm{Ou}$ seja, a presença da mulher na esfera familiar do trabalho doméstico é peça-chave à reprodução do modo de produção capitalista (ÁVILA; FERREIRA, 2014), mas também é um mecanismo de dominação, exploração e opressão. Por seu turno, Silvia Camurça (2007) argumenta que a divisão sexual do trabalho é um instrumento de dominação "porque quando as mulheres fazem apenas o trabalho doméstico, para sua própria família, perdem autonomia econômica, tornam-se dependentes, portanto, devedoras e subordinadas àqueles que garantem as condições de sua sobrevivência, em geral, homens, sejam maridos, filhos, cunhados ou genros".

Dessa perspectiva, o trabalho doméstico não remunerado, sobretudo quando realizado pelas mulheres das classes subalternas (ÁVILA, 2009; FEDERICI, 2017; FERREIRA, 2017), é um mecanismos que, dentre outros, determina a reprodução da força de trabalho e que, por efeito, mantém elevados os níveis de exploração do conjunto da classe trabalhadora, especialmente, nas economias periféricas dependentes como é o caso da economia brasileira. Ferreira (2017, p. 94), ao repor o pensamento de outras autoras feministas, destaca que "o trabalho realizado diariamente pelas mulheres no espaço reprodutivo possibilita ao capitalista a segurança da reprodução e a perpetuação da força de trabalho e, dessa maneira, garante também a reprodução e a manutenção da própria lógica do capital".

No Brasil, os estudos e pesquisas mais atuais revelam que ainda há pouco investimento do Estado em políticas públicas que equilibre a carga cotidiana de trabalho doméstico e de cuidados entre os sexos e, portanto, a sobrecarga da mulher no tocante ao trabalho doméstico não remunerado ainda é uma questão a se problematizar na realidade brasileira.

Nesses termos, destaca-se primeiramente que a insuficiência ou até ausência de serviços de creches, escola em tempo integral, lavanderias, restaurantes populares públicos, serviços de convivência para pessoas idosas e com deficiência, dentre outros, tem ampliado os mecanismos de "uso do tempo social das mulheres na esfera da reprodução social privada como compensação da ausência ou insuficiência da ação pública" (FERREIRA, 2017).

Frente a essa realidade que mantém, majoritariamente, o trabalho doméstico não remunerado e de cuidados sob a responsabilidade da mulher, inclusive, àquela que exerce trabalho mercantil - manifestando a "existência de uma jornada de trabalho extensiva, intensiva e intermitente" (ÁVILA, 2009) “, recorremos à PNAD Contínua de 2017 a fim de revelar o quantum de horas a mulher é obrigada a se "dedicar" às atividades domésticas, especialmente nas periferias que registram a ausência e/ou insuficiência dos serviços públicos de reprodução social.

De acordo com a Pnad Contínua 2017 - Outras formas de trabalho ${ }^{10}$-, apesar de os homens com maior escolaridade estarem se dedicando mais aos trabalhos domésticos, ainda persistem as diferenças de horas entre os sexos quanto às obrigações com o trabalho doméstico não remunerado e de cuidados. Conforme exposto na pesquisa, as mulheres "dedicaram" quase o dobro de horas do que os homens às atividades domésticas e aos cuidados de pessoas, destacando que, enquanto para elas a média de horas semanais ficou em 20,9 horas, eles dedicaram, em média, 10,8 horas por semana. Ademais, quando a mulher tem filhos e/ou é responsável pelos cuidados de outros familiares e não tem acesso aos serviços e equipamentos públicos que facilitam a realização do trabalho doméstico e de cuidados, essas horas tendem a dobrar, no mínimo.

Desde a crise do capital dos anos 1970, o Estado reduz sua intervenção social e segue a batuta dos interesses de acumulação do capital buscando se apropriar do tempo e da força de trabalho da mulher. Segundo destaca David Harvey (2016, p. 176, grifo do autor), "nos últimos tempos, parte do ethos e do programa político neoliberal tem sido repassar o máximo possível de custos da reprodução social para a população em geral, no intuito de aumentar a taxa de lucro do capital, reduzindo a carga tributária”.

Quando analisamos as particularidades do Estado neoliberal no Brasil, concordamos com as análises de Ferreira (2017, p. 26) de que "a apropriação do tempo das mulheres não é um epifenômeno da implementação [...] das políticas sociais; é, antes, uma mediação constitutiva das políticas sociais no capitalismo, acentuadas no período de hegemonia neoliberal e acirradas no contexto de crise e restauração do capital" [...].

No contexto dos governos sociais-liberais ${ }^{11}$ do PT, o reconhecimento do trabalho doméstico não remunerado e sua vinculação à política de Previdência Social sob critérios de "inclusão social" modelados em consonância com os organismos internacionais a exemplo do FMI e Banco Mundial, convergiram com as tendências que se apontam para as políticas de Seguridade Social cujo sujeito central é a família, personificado na "mulher-mãe-esposa-dona-de-casa" (DUQUE-ARRAZOLA, 2004). 
Considerando o Sistema Especial de Inclusão Previdenciária, entendemos que será sempre menos oneroso para o capital e para o seu Estado reconhecer, "valorizar" e garantir às "donas de casa de baixa renda" o acesso à Previdência Social sob uma perspectiva assistencial-contributiva " ainda que com alíquota reduzida -, a ter que pagar salários que garantam a reprodução social do conjunto da classe trabalhadora e ampliar e universalizar serviços sociais públicos ${ }^{12}$ nas cidades e nas periferias que 'libertem' as mulheres do fardo cotidiano com a jornada intensa em torno dos trabalhos domésticos e, diga-se, com aqueles denominados de cuidados (BARRETO, 2019).

Sendo assim, nunca é demais lembrar que a estruturação da Seguridade Social na Carta Magna de 1988 inaugurou a trilha para a consolidação do direito humano à proteção social no Brasil que, quando efetivado em um amplo sistema de proteção social, público e universal (nos termos de Boschetti, 2016) ${ }^{13}$, tem o potencial de constituir padrões civilizatórios - ainda que nos limites do capital -, criando e ampliando políticas, bens e serviços sociais necessários à reprodução social da classe trabalhadora e, em termos, reduzir o peso do trabalho doméstico e de cuidados para as mulheres, sobretudo, àquelas mais pauperizadas.

Do nosso entendimento, quanto mais distante a universalização do direito humano à proteção social, e, em consequência, do seu pilar estruturador: a Seguridade Social; tanto mais exploradas e oprimidas estarão as mulheres das classes subalternas, principalmente, em uma conjuntura cujos números oficiais no Brasil apontam para um crescimento de quase 13 milhões de desempregados/as e mais outros milhões de desalentados/as ou em trabalhados informais, ou seja, sem qualquer proteção trabalhista ${ }^{14}$.

A nosso ver, em uma conjuntura de avanços neoliberais fundamentados no projeto e nos processos de expansão seletiva e privatista das políticas de Seguridade Social cujos pressupostos são de exploração do tempo, dos corpos e do trabalho das mulheres das classes subalternas, tendencialmente, o já frágil direito à Seguridade Social tornar-se-á cada vez mais focalizado e seletivo e regido por requisitos de "inclusão social" constituídos sob pressupostos liberais que a cada nova crise do capital parece manter mais fortalecidos os mecanismos políticos e ideológicos de controle das mulheres.

Nesses termos, o enfrentamento das políticas neoliberais parece exigir o florescer de um sujeito feminista crítico, revolucionário e de resistência à lógica do capital e de seus mecanismos de reprodução da exploração e opressão às mulheres.

\section{Considerações finais}

Mauro Iasi (2013) em uma reflexão sobre $O$ Direito e a Luta pela Emancipação Humana, lança a seguinte questão: nós que estamos comprometidos com a emancipação humana ${ }^{15}$ devemos nos mobilizar para defender as fronteiras da emancipação política ameaçada pela reversão civilizatória do capitalismo imperialista? ${ }^{16}$

A resposta dada pelo historiador segue sob duas perspectivas: resistência e revolução, a saber:

[...] Evidente que devemos mobilizar nossas forças na resistência contra a regressão de direitos e patamares civilizatórios alcançados, simplesmente porque temos por dever de defender a vida e os trabalhadores [e trabalhadoras] contra os ataques do capital, mas isso não pode se converter numa defesa da sociedade capitalista ou dos "aspectos positivos" dessa sociedade, pelo simples fato de que é a ordem burguesa, a mesma que produziu a emancipação política, que agora a ameaça. Não nos cabe defender o capitalismo contra ele próprio, pois desde o início apontamos para o fato que seu desenvolvimento caminhava no sentido da desumanização e que a verdadeira emancipação ia, necessariamente, além de seus limites societários. (IASI, 2013, p. 189).

Em consonância com a perspectiva acima, entendemos que a luta pela manutenção e ampliação de direitos, sobretudo, os direitos sociais, é uma luta fundamental em economias periféricas, como é o caso do Brasil. Diríamos que em regiões da periferia do capital, as lutas por direitos sociais são lutas necessárias, pois constroem nas mulheres - enquanto sujeitos da classe trabalhadora e das classes subalternas - possibilidades históricas reais de existência e organização para resistências coletivas à exploração, dominação e opressão. Entretanto, em tempos de contrarreformas neoliberais, as lutas feministas por direitos não podem prescindir de uma compreensão analítica sobre os mecanismos estruturais e conjunturais que aprisionam, discriminam, exploram e oprimem as mulheres, em especial, as mulheres das classes subalternas, dentre os quais: a divisão sexual do trabalho que reproduz e as recoloca em completa "servidão doméstica" (PATEMAN, 1993) tanto aos homens quanto para o Estado.

Dessa compreensão e frente à crise civilizatória que vivemos nos tempos atuais, a luta por direitos além de se pautar por pressupostos internacionalista, antineoliberal e anticapitalista (ARRUZA, BHATTACHARYA, 
FRASER, 2019), não deve ser um fim em si mesmo, mas se ancorar na força de que a liberdade de uma mulher exige a liberdade de todas, o que, por sua vez, e, ao mesmo tempo, pressupõe a construção de uma consciência coletiva da classe trabalhadora para a transformação da ordem patriarcal-racista-capitalista, correspondendo ao desafio da construção da emancipação humana na sua totalidade (CISNE, 2014).

Nesses termos, as lutas feministas de hoje estão também desafiadas, ainda nos tempos capitalistas-neoliberais, em defender além do direito humano à proteção social, um projeto revolucionário constituído por processos que apontem para a emancipação das mulheres. Ou como diz Mirla Cisne, que não admita "práticas que reproduzam qualquer tipo de exploração ou opressão [...], que liberta e emancipa, que quebra todas as cercas e formas de propriedade privada, inclusive sobre o corpo da mulher". (CISNE, 2014, p. 253).

\section{Referências}

AGÊNCIA IBGE. PNAD Contínua 2017: realização de afazeres domésticos e cuidados de pessoas cresce entre os homens, mas mulheres ainda dedicam quase o dobro do tempo. Notícias, 18 abr. 2018. Disponível em: https://agenciadenoticias.ibge.gov.br/agenciasala-de-imprensa/2013-agencia-de-noticias/releases/20911-pnad-continua-2017-realizacao-de-afazeres-domesticos-e-cuidados-depessoas-cresce-entre-os-homens-mas-mulheres-ainda-dedicam-quase-o-dobro-do-tempo. Acesso em: 22 set. 2019.

AGÊNCIA IBGE. PNAD Contínua tri: taxa de subutilização da força de trabalho é de 24,7\% no primeiro tri de 2018. Notícias, 17 maio 2018. Disponível em: https://agenciadenoticias.ibge.gov.br/agencia-sala-de-imprensa/2013-agencia-de-noticias/releases/21246-pnadcontinua-tri-taxa-de-subutilizacao-da-forca-de-trabalho-e-de-24-7-no-primeiro-tri-de-2018. Acesso em: 14 out. 2018.

ANFIP/DIEESE. A reforma da previdência e os servidores públicos: retrocesso nas aposentadorias e pensões. Fundação ANFIP, Brasília/DF, 2017. [Nota técnica, n. 181] Disponível em: https://www4.anfip.org.br/doc/publicacoes/ Documentos_21_11_2017_10_53_44.pdf. Acesso em: 22 de setembro de 2019.

ARRUZA, C.; BHATTACHARYA, T.; FRASER, N. Feminismo para os 99\%: um manifesto. São Paulo, Boitempo, 2019.

ÁVILA, M. B. de M. O tempo do trabalho das empregadas domésticas: tensões entre dominação/exploração e resistência. 2009. $321 \mathrm{f}$. Tese (Doutorado)- Universidade Federal de Pernambuco, Departamento de Sociologia, Recife, 2009.

ÁVILA, M. B.; FERREIRA, V. (org.). Trabalho remunerado e trabalho doméstico no cotidiano das mulheres. SOS Corpo; Instituto Feminista para a Democracia. Recife, 2014.

BARRETO, L. M. A (ultra) precarização como condição de acesso à Previdência Social. Revista Ser Social: Previdência Social e Trabalho, Brasília, v. 18, n. 39, 2016. [Ensaio]

BARRETO, L. M. Seguridade Social no Brasil e os movimentos das mulheres pelo direito à aposentadoria das "donas de casa de baixa renda": contradições e tendências. Tese (Doutorado)- Universidade Federal de Pernambuco, Departamento de Serviço Social, Recife, 2019.

BOSCHETTI, I. Assistência Social e Trabalho no Capitalismo. São Paulo: Cortez, 2016.

BRASIL. Constituição da República Federativa do Brasil. Brasília/DF, 1988.

BRASIL. Lei n. 12.470, de 31 de agosto de 2011. Altera os arts. 21 e 24 da Lei no 8.212, de 24 de julho de 1991, que dispõe sobre o Plano de Custeio da Previdência Social [...]. Disponível em: http://www.planalto.gov.br/ccivil_03/_Ato2011-2014/2011/Lei/L12470.htm. Acesso em: 25 out. 2019.

BRESSER PEREIRA, L. C. Reforma do Estado para a Cidadania: a reforma gerencial brasileira na perspectiva internacional. 34. ed. São Paulo, Brasília, ENAP, 1998.

CAMURÇA, S. O Patriarcado e a Situação das Mulheres. Recife, SOS Corpo, 2007.

CASTELO, R. O Social-Liberalismo: auge e crise da supremacia burguesa na era neoliberal. São Paulo: Expressão Popular, 2013.

CISNE, M. Feminismo e consciência de classe no Brasil. São Paulo: Cortez, 2014.

DIEESE. PEC 06/2019: as mulheres outra vez na mira da reforma da Previdência. Nota Técnica, março de 202. Disponível em: https:/ /www.dieese.org.br/notatecnica/2019/notaTec202MulherPrevidencia.html. Acesso em: 25 out. 2019.

DUQUE-ARRAZOLA, L. O lugar das mulheres nas políticas de Assistência Social: um estudo sobre a experiência do Programa de Erradicação do Trabalho Infantil em Pernambuco. 2004. 297f. Tese (Doutorado)"Universidade Federal de Pernambuco, Departamento de Serviço Social. Recife, 2004.

FEDERICI, S. Calibã e a Bruxa: Mulheres, Corpo e Acumulação Primitiva. [S. 1.]: Elefante, 2017.

FERREIRA, V. M. Apropriação do tempo de trabalho das mulheres nas políticas de saúde e reprodução social: uma análise de suas tendências. 2017. 202f. Tese (Doutorado)"Universidade Federal de Pernambuco, Departamento de Serviço Social. Recife, 2017.

GRANEMANN, S. PEC 287/16: falácias para a desconstrução dos direitos do trabalho. Revista Ser Social: Previdência Social e Trabalho, Brasília, v. 18, n. 39, 2016. [Ensaio]

HARVEY, D. 17 contradições e o fim do capitalismo. São Paulo: Boitempo, 2016.

IASI, M. L. O Direito e a luta pela emancipação humana. In: FORTI, V.; BRITES, M. C. (org.). Direitos humanos e serviço social: polêmicas, debates e embates. 3. ed. Rio de Janeiro: Lumen Juris, 2013. 
INSTITUTO NACIONAL DO SEGURO SOCIAL (INSS). Ministério da Economia. Facultativo de baixa renda (dono de casa). Categorias de segurados, 5 jun. 2019. Disponível em: https://www.inss.gov.br/orientacoes/categorias-de-segurados/facultativo-de-baixarenda-dona-de-casa/. Acesso em: 10 dez. 2019.

KERGOAT, D. Divisão sexual do trabalho e relações sociais de sexo. In: HIRATA, H. (org.) [et al.]. Dicionário Crítico do Feminismo. São Paulo: UNESP, 2009.

MARX, K. A questão judaica. 4. ed. São Paulo: Centauro, 2002.

MOTA, A. E. Cultura da Crise e seguridade social: um estudo sobre as tendências da previdência e da assistência social brasileira nos anos 80 e 90. 4. ed. São Paulo: Cortez, 2008.

OSÓRIO, J. Padrão de Reprodução do Capital: uma proposta teórica. In: FERREIRA, C.; OSÓRIO, J.; LUCE, M. (org.). Padrão de reprodução do capital: contribuição da teoria marxista da dependência. São Paulo: Boitempo, 2012.

PATEMAN, Carole. O Contrato Sexual. Rio de Janeiro, Paz e Terra, 1993.

SINGER, A. Os sentidos do Lulismo: reforma gradual e pacto conservador. São Paulo: Companhia das Letras, 2012.

\section{Notas}

1 Data de 2005 a alteração no artigo 201 por meio dos parágrafos $\S 12 \S 13$ da CF/88 que tratou de criar um Sistema Especial de Inclusão Previdenciária para trabalhadores na condição de baixa renda. Os parágrafos 12 e 13 do artigo 201 da Constituição Federal de 1988 afirmam respectivamente que: "Lei disporá sobre Sistema Especial de Inclusão Previdenciária para atender a trabalhadores de baixa renda e àqueles sem renda própria que se dediquem exclusivamente ao trabalho doméstico no âmbito de sua residência, desde que pertencentes a famílias de baixa renda, garantindo-lhes acesso a benefícios de valor igual a um salário-mínimo"; e, "o sistema especial de inclusão previdenciária de que trata o $\$ 12$ deste artigo terá alíquotas e carências inferiores às vigentes para os demais segurados do regime geral de previdência social".

2 Ainda que não seja objeto desse artigo problematizar a suposta conquista social de formalizar os informais sob pressupostos neoliberais, é importante destacar que ao MEI basta realizar a contribuição mensal, via Documentação de Arrecadação do Simples Nacional-DAS/MEI “, para adquirir o direito aos benefícios previdenciários. No caso da "dona de casa de baixa renda", a contribuição mensal por si só não é suficiente. Observa-se que a essas mulheres é exigido cumprir com outros requisitos, conforme destacado acima.

3 Vale salientar que a Lei n. 12.470/2011 é extensiva ao dono de casa de baixa renda. Porém, o mesmo não será objeto de reflexão neste artigo.

4 Instituto Nacional do Seguro Social (INSS). Ministério da Economia (2019).

5 Dado o limite desse artigo que nos impede de problematizar esse debate, entendemos que uma justa a posentadoria para as donas de casa de baixa renda está inscrita na defesa da ampliação do parágrafo $8^{\circ}$ do artigo 195 da Constituição Federal de 1988 que, em analogia às/aos trabalhadoras/es rurais, garantiria o direito aos benefícios previdenciários para esse segmento de mulheres na condição de Seguradas Especiais (BARRETO, 2019).

6 O que se argumenta como expansão seletiva e privatista da Previdência Social encontra seus fundamentos no "pós 64" (MOTA, 2008), mas se consolida com força política a partir da adesão do Estado brasileiro às políticas neoliberais. Nos anos 1990, sob a regência dos organismos internacionais, a exemplo do FMI e Banco Mundial, que ganhou força no Brasil as políticas neoliberais de "reforma do Estado para a Cidadania" (BRESSER PEREIRA, 1998) a fim de controlar o suposto déficit da Previdência Social e garantir um sistema de previdência básica. Nas palavras daquele autor, "o Estado deveria garantir um sistema de previdência básica, deixando em seguida o sistema complementar, que poderia ser obrigatório até um nível intermediário de renda, para as empresas seguradoras do setor privado". (BRESSER PEREIRA,1998, p. 331). Ao longo dos anos 1990e 2000 a Previdência Social, tanto no RGPS quanto no RPPS, sofreu ataques que foram desde "reforma" à CF/1988 - de FHC (EC 20/98), Lula (EC 41/03) - à instituição de medidas infraconstitucionais inauguradas pela então presidenta Dilma Rousseff que fez avançar os regimes de previdência privada (a exemplo do FUNPRESP) e endureceu os critérios de acesso a pensões para as mulheres por meio da Lei n. 13.135/15 (GRANEMANN, 2016). Hoje, em tempos de avanços ultraneoliberais e neoconservadorismo, a Previdência Social sofre mais um ataque através da EC 103/19, colocando as "mulheres na mira da reforma" (DIEESE, 2019). Em que pese o caráter destrutivo da EC 103/19, chama-nos atenção que o SEIP não foi objeto da referida "reforma" (BARRETO, 2019).

7 Nesta análise não estamos considerando os efeitos regressivos da EC 103/19 que, apesar de manter o tempo mínimo de contribuição de 15 anos para “donas de casa de baixa renda", apontam, para fins de aposentadoria no regime geral, uma ampliação da idade e da alíquota de contribuição para recebimento de um salário mínimo, o que poderá significar mais anos de exploração e opressão para esse segmento.

8 Em 2003, sob os auspícios da segunda contrarreforma da Previdência Social, alguns movimentos de mulheres e organizações feministas se organizaram a fim de reivindicar do Estado o direito à aposentadoria para as "donas de casa de baixa renda", por meio do reconhecimento do trabalho doméstico não remunerado como trabalho e sua conseqüente inclusão no artigo 201 que trata da Previdência Social. Esse estudo está disponível em Barreto (2019).

9 Aqui reside a chave de produção de mais-valia. (OSÓRIO, 2012).

10 Agência IBGE. PNAD Contínua 2017 (2018).

11 Apartir da crise de hegemonia do receituário ortodoxo neoliberal naAmérica-latina, ganha força política a sua face mais "humanista", intitulada por Castelo (2013), como a "segunda variante ideológica do neoliberalismo": o social-liberalismo. Na compreensão do autor, nesta segunda variante ideológica o neoliberalismo e seus intelectuais promovem um "sincretismo entre o mercado e o Estado, imaginariamente capaz de instaurar a justiça social, ou seja, as desigualdades socioeconômicas deixaram de ser uma solução para questões específicas do capitalismoe passaram a ser um dilema social a ser tratado pela burguesia e seus intelectuais" (CASTELO, 2013, p. 247). 
12 Destacam-se aqui os serviços de creches, restaurantes públicos, lavanderias, escolas em tempo integral, serviços de convivência e cuidados para idosos e pessoas com deficiência, dentre outros.

13 Segundo Boschetti (2016, p. 26), sistema de proteção social é o "conjunto organizado, coerente, sistemático, planejado de diversas políticas sociais, financiado pelo fundo público e que garante a proteção social por meio de amplos direitos, bens e serviços sociais, nas áreas de emprego, saúde, previdência, habitação, assistência social, educação, transporte, entre outros bens e serviços públicos".

14 Agência IBGE. PNAD Contínua tri (2018).

15 Para Marx (2002), "a emancipação humana é o horizonte a se vislumbrar enquanto ruptura, material e moral ao homem egoísta burguês".

16 Iasi (2013, p. 189).

\section{Laudicena Maria Pereira Barreto}

laudicena.barreto@gmail.com

Doutora em Serviço Social pelo Programa de Pós-graduação em Serviço Social da Universidade Federal de Pernambuco (UFPE)

Professora do Departamento de Serviço Social da Universidade Federal de Pernambuco (UFPE)

\section{UFPE}

Centro de Ciências Sociais Aplicadas

Av. dos Economistas, s/n - Cidade Universitária

Recife - Pernambuco - Brasil

CEP: 50.000-000

\section{Agradecimentos}

Às Professoras Doutoras Ana Elizabete Mota e Ivanete Boschetti pelas contribuições ao longo do processo de doutoramento, tanto na UFPE como na UnB; assim como, às pesquisadoras e militantes feministas, especialmente, àquelas referenciadas neste artigo.

\section{Agência financiadora}

Registramos o apoio do CNPq ao longo do doutoramento através de bolsa para Doutorado-sanduíche no Programa de Pós-graduação em Política Social da UnB, de agosto de 2017 a janeiro/2018, processo n. 300284/2017-9.

\section{Contribuições das autoras}

Não se aplica.

Aprovação por Comitê de Ética e consentimento para participação

Não se aplica.

Consentimento para publicação

Consentimento da autora.

Conflito de interesses

Não há conflito de interesses. 